ORIGINAL ARTICLE

\title{
The neurodevelopmental progress of infants less than 33 weeks into adolescence
}

\author{
F O'Brien, S Roth, A Stewart, L Rifkin, T Rushe, J Wyatt
}

Arch Dis Child 2004;89:207-211. doi: 10.1136/adc.2002.006676

See end of article for authors' affiliations .....................

Correspondence to: Dr F O'Brien, Department of Paediatrics, The Rayne Institute, 5 University Street, London WC1E 6JJ, UK; f.o'brien@ucl.ac.uk

Accepted 9 April 2003

\begin{abstract}
Background: Several studies have shown an increased incidence of neurodevelopmental impairment in very preterm survivors at school age compared with controls.

Aim: To compare findings in the same cohort at 8 years and 15 years.

Methods: A total of 151 of the 224 eligible infants born before 33 weeks of gestation from 1979 to 1982 , and who were living in the UK, were assessed at 8 and 15 years. Items common to both assessments were compared to evaluate changes in neurodevelopmental function. The assessment included a structured neurological examination, psychometric tests using the WISC-R (in subjects born in 1981-82), a test of visuomotor integration (Beery), and a school questionnaire.

Results: There was a significant increase in the proportion of subjects classified as impaired with disability from $11 \%$ at 8 to $22 \%$ at $14-15$ years of age. The proportion of subjects classified as impaired without disability increased from $16 \%$ at 8 to $26 \%$ at $14-15$ years of age. Full scale IQ decreased from 104 to 95 from childhood to adolescence, and more adolescents (24\%) were requiring extra educational provision than they had at the age of 8 years (15\%).

Conclusion: Results indicate that between the ages of 8 and 15 years in this cohort of very preterm survivors there is an apparent deterioration in neurodevelopmental outcome category, cognitive function, and extra educational support. It is not clear whether this represents a genuine deterioration in neurocognitive function or whether it represents the expression of pre-existing cerebral pathology in an increasingly complex environment.
\end{abstract}

espite increases in the survival rates of preterm infants, little is known about the long term outcome into adolescence. Numerous studies published over the past 20 years have shown that there has been a significant improvement in the survival of preterm infants. ${ }^{1-3}$ The current evidence about whether this has led to an increase in the incidence of cerebral palsy is conflicting. ${ }^{3-7}$ The North of England Collaborative Cerebral Palsy Survey has recently reported that $50 \%$ of children with cerebral palsy were born preterm. ${ }^{8}$ In addition, children not displaying classical neurological signs are still vulnerable to problems later in childhood, particularly behavioural, attention, and cognitive. ${ }^{9}$ Despite these concerns, the vast majority of children who were born prematurely are now entering mainstream education, and attention is increasingly being turned to the quality of life of these survivors and their educational and behavioural status.

Compared with full term, age matched controls, very low birth weight children perform less well in a variety of cognitive and psychological tests, and have an increased requirement for extra educational assistance during the first decade..$^{9-13}$ Little is known about outcome beyond the first decade, and in particular whether there is any change in morbidity and level of educational achievement during the progression from childhood into adolescence. The aim of this study therefore was to investigate the neurodevelopmental progress in a cohort of preterm survivors from a single tertiary perinatal centre, by comparing the results of detailed neurodevelopmental assessment at 8 and 14 years.

\section{METHODS \\ Subjects}

A total of 224 of 320 infants born before 33 weeks of gestational age between 1979 and 1982 and admitted within the first week of life to University College London Hospital (a tertiary referral neonatal unit) survived to discharge from hospital. This cohort underwent cranial ultrasound examination in the first weeks of life and neurodevelopmental assessment at 1 year, ${ }^{14}$ and 4 years of age. ${ }^{15}$ At 8 years of age 207 children received detailed assessment. ${ }^{16}$ Of these, 151 children were available for assessment at 14-15 years. For logistical reasons only children living in the UK were contacted for assessment at 14-15 years of age.

\section{Assessment at 8 years}

At 8 years of age assessments were performed by a paediatrician, an audiometrician, and a psychologist, none of whom had any information about the perinatal histories. The assessment by the paediatrician consisted of a conventional and a structured neurological examination, ${ }^{16}$ a test of visual acuity with Snellen charts, ${ }^{17}$ a test of motor impairment, ${ }^{18}$ and the Beery test of visuomotor integration (VMI). ${ }^{19}$ The child's school performance was recorded from a school report and a parental questionnaire. A pure-tone audiogram was performed by an experienced audiometrician in a soundproofed room.

Psychological assessment included tests of cognitive function using the Wechsler Intelligence Scales for Children Revised (WISC-R), ${ }^{20}$ the Kaufman Assessment Battery for Children (K-ABC), ${ }^{21}$ and a behavioural checklist. ${ }^{22}$ The WISC-R and K-ABC were usually administered in the follow up clinic on two separate days, not more than one month apart.

If a child was so disabled that the tests of cognitive and fine motor function and visuomotor integration could not be completed, arbitrary scores were assigned. ${ }^{15}$ The scores assigned were equivalent to $3 \mathrm{SD}$ below the test mean for the WISC-R and K-ABC, below the 5th centile for the Beery VMI and as a maximum error score for the TOMI. 


\section{Assessment at 14-15 years}

At 14-15 years of age the assessments were carried out by a psychologist, a paediatrician, a neurologist, and a psychiatrist, all of who were blind to both perinatal events and the results of the assessment at 8 years. The paediatrician performed a neurological examination ${ }^{16}$ and a test of visualmotor integration. ${ }^{19}$ The paediatrician also performed the premorbid adjustment scale, ${ }^{23}$ which assesses school performance and social adjustment, the Rutter behavioural score, ${ }^{24}$ and gave the parents a structured interview. The psychologist administered the Schonnel test for reading age, ${ }^{25}$ and the WISC-R intelligence quotient ${ }^{20}$ was performed in children who had been born in 1981 and 1982. A neurologist also independently carried out a standardised neurological examination. Information regarding behaviour and school performance was also sought.

\section{Definition of impairment and disability}

At both 8 and 14 years of age children were assigned to three outcome groups: impairment leading to disability; impairment without disability; and no impairment. The definitions for these outcome groups are provided in the Appendix.

In order to ensure consistency, the neurological assessment and the assignment of subjects to outcome category was supervised by the same researchers (SR and ALS) at both ages.

\section{Data analysis}

The results of the assessments were coded and analysed by computer using the Wilcoxon signed rank test, $\chi^{2}$ test, and paired $t$ test (Statistical Package for Social Sciences, version 7.0).

\section{Ethics}

Consent for the follow up study was obtained from the Joint University College London/University College Hospital Committee on the Ethics of Human Research and the Joint Medical Ethical Committee of the Institute of Neurology and National Hospital for Neurology and Neurosurgery.

\section{RESULTS}

At 14-15 years the 151 subjects who were assessed represented $67.4 \%$ of the eligible cohort. At least 11 children were living abroad and unable to attend for assessment. We were therefore able to assess $71 \%$ of available survivors living in the UK. A comparison between surviving infants who were assessed at 14-15 years and those who were not, showed that there was no significant difference for gestational age (29.3, SD $2.1 \quad v$ 30.1 SD 1.7). There was a weakly significant difference $(p=0.03)$ in birth weight between the two groups (1306 g, SD $319 \mathrm{~g}$ assessed $v 1449 \mathrm{~g}$, SD $360 \mathrm{~g}$ not assessed). A further comparison was made of the neurodevelopmental status at 1 and 8 years of age; there was no significant difference between those who were assessed at 14-15 years and those who were not. It seems likely therefore that the population studied was representative of the cohort as a whole. Table 1 shows the perinatal characteristics of the subjects.

Table 2 shows the number (and percentage) of children classified as either normal, impaired without disability, or

Table 1 Perinatal characteristics

\begin{tabular}{ll}
\hline Gender, male:female & $84: 67$ \\
Gestation (weeks), median (range) & $29(24-32)$ \\
Birth weight (g), median (range) & $1282(600-2230)$ \\
SGA (<10th centile), n (\%) & $6(4)$ \\
\hline *Delivery data missing for one subject.
\end{tabular}

Table 2 Comparison of neurodevelopmental outcome category during childhood and adolescence for expreterm infants born $<33$ weeks gestation $(n=151)$

\begin{tabular}{|c|c|c|c|c|}
\hline & \multicolumn{2}{|c|}{8 years } & \multicolumn{2}{|c|}{$14-15$ years } \\
\hline & $n$ & $(\%)$ & $n$ & (\%) \\
\hline $\begin{array}{l}\text { Not impaired } \\
\text { Impairment } \\
\text { Impair + disability }\end{array}$ & $\begin{array}{l}99 \\
35 \\
17\end{array}$ & $\begin{array}{l}(65 \%) \\
(23 \%) \\
(11 \%)\end{array}$ & $\begin{array}{l}40 \\
77 \\
34\end{array}$ & $\begin{array}{l}(27 \%) \\
(51 \%) \\
(22 \%)\end{array}$ \\
\hline
\end{tabular}

impaired with disability at both 8 years and $14-15$ years. It can be seen that the proportion of subjects classified as disabled doubled from $11 \%$ at 8 years to $22 \%$ at 14 years.

In order to establish which components of the neurodevelopmental assessment contributed to the observed apparent deterioration between 8 and 15 years, we analysed in more detail the results of the WISC-R, VMI, and neurological examination. Table 3 illustrates the results of the psychometric test (WISC-R) performed on children born 1981-82 and the VMI test. Performance IQ was calculated from five subsets at 8 and only two subtests at 15; for this reason we have only displayed the comparable two subtests in which a deterioration can be seen between the two ages. Figure 1 shows the changes in full scale IQ. Using the Wilcoxon signed rank test we found a statistically significant difference in the children with an IQ $>84$ at 8 years $(n=56 ; 85 \%)$ compared to the same test results at 14 years $(n=45 ; 68 \%$; $=0.004)$. Similarly, the proportion of children with an IQ of 70-84 at 8 years $(n=8 ; 12 \%)$ had increased $(n=16 ; 24 \%)$ by adolescence $(p=0.002)$. There was no significant change in the proportion of 8 year olds with an IQ $<70$ when measured at 14 years.

Table 4 shows the neuromotor test results for the whole cohort at 8 and 14-15 years. It can clearly be seen that the proportion of subjects classified as normal at 8 years has decreased from $82 \%$ to $65 \%$ at 15 years. There has been a corresponding increase in impairment from 13\% to 30\% from childhood to adolescence with little change in those classed as disabled.

Table 5 shows the provision of extra educational assistance at the two age groups. There was a significant increase in the provision of assistance at the older age group. This was almost entirely due to increased assistance for children in mainstream schools.

\section{DISCUSSION}

We have shown that there is an apparent deterioration in neurodevelopmental status between the ages of 8 and 15 years in a cohort of preterm children. The most striking change was an increase in the proportion of children previously assessed as normal who had mild impairments at 15 years. The decline in assessment scores involved both cognitive and neurological measures. In line with these findings there was an increase in the number and proportion of subjects requiring extra educational provision in adolescence compared with 8 years of age.

\section{Comparison with other studies}

Our results are consistent with those of other studies documenting the prevalence of neurodevelopmental problems during both the childhood years and adolescence, ${ }^{26}$ although methodological differences make precise comparison difficult. Pharoah and colleagues, ${ }^{27}$ in a study of 8 year old children with birth weights $<2000 \mathrm{~g}$ found $11.6 \%$ had definite motor impairment and a further $21.6 \%$ had moderate motor impairment as assessed by the TOMI at 8 years. They 
Table 3 Psychometric test scores at 8 years and adolescence of infants born $<33$ weeks gestation $(n=66)$

\begin{tabular}{llll}
\hline & \multicolumn{2}{l}{ Age at test } & \\
\cline { 2 - 4 } & $\mathbf{8}$ years & $\mathbf{1 4 - 1 5}$ years & $\mathbf{P}$ \\
\hline WISC-R full scale IQ, mean (SD) & $104(18)$ & $95(18)$ & $<0.0001^{*}$ \\
WISC subscales, mean (SD) & $98(16)$ & $95(21)$ & $\mathrm{NS}$ \\
Performance IQ & $11(3)$ & $9(3)$ & $<0.0001^{*}$ \\
Picture completion & $10(3)$ & $9(3)$ & $<0.0001^{*}$ \\
Block design & $109(19)$ & $95(18)$ & $<0.0001^{*}$ \\
Verbal IQ & $12(4)$ & $10(3)$ & $<0.0001^{*}$ \\
Similarities & $12(3)$ & $10(4)$ & $<0.0001^{*}$ \\
Vocabulary & $42(28)$ & $54(38)$ & $\mathrm{NS}$ \\
VMI, mean (SD) & & & \\
\hline *Paired $t$ test. & & & \\
tWilcoxon signed rank test. & & &
\end{tabular}

also found lower reading ages and WISC scores compared with controls.

Cognitive outcome at 8 years of age in our study was comparable to the results of other studies. For example, Saigal and colleagues ${ }^{26}$ found that extremely low birth weight children at the age of 8 years had mean WISC-R full scale IQ of 91 compared with matched controls who had IQ scores of 104.

In our cohort the proportion of children receiving extra educational provision at 8 years of age was $15 \%$. This is comparable with the estimate of the 1976 Court Report, ${ }^{28}$ which estimated that $14 \%$ of all children in the general UK population received extra educational provision. However, several other studies from other countries have found a greater requirement for extra educational provision. Horwood and colleagues ${ }^{29}$ in New Zealand found $22.9 \%$ of children with birth weights of $1000-1499 \mathrm{~g}$ and $26.9 \%$ with birth weights $<1000$ g required extra educational assistance at 7-8 years. A large population study from the Netherlands of preterm and very low birth weight infants assessed at 9 years of age, found that $19 \%$ were in special schools and $38 \%$ of children in mainstream schools required extra help. ${ }^{30} \mathrm{~A}$ cohort of children in Liverpool, with birth weights $<1250 \mathrm{~g}$, were also found to perform significantly less well than age matched classmates in a range of educational measures. ${ }^{31} 32$

In contrast to the extensive outcome reporting at early school age, much less has been reported about outcome into

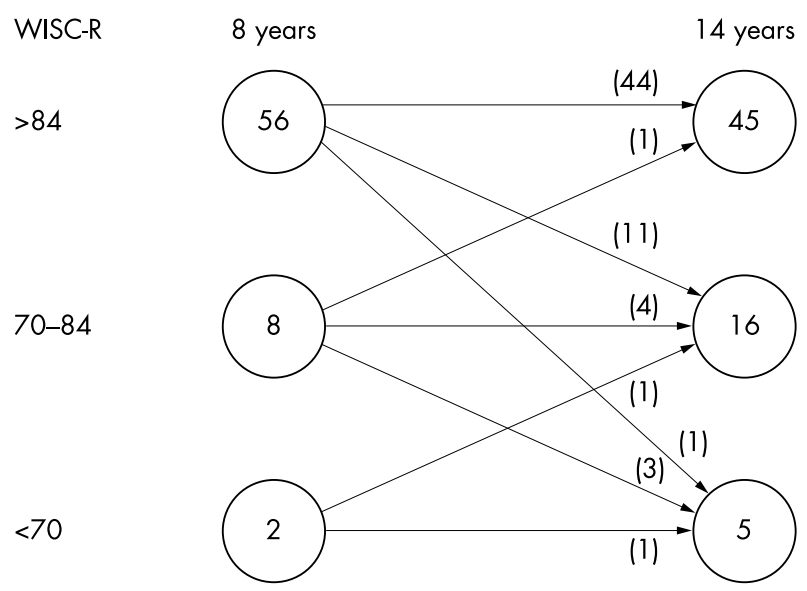

Figure 1 Psychometric test scores (WISC-R) at 8 years and adolescence $(n=66)$ showing movement of individuals according to their full scale IQ. Each category corresponds to one standard deviation from the mean. Numbers in brackets show the number of subjects whose full scale IQ improved, remained constant, or declined, from age 8 years to adolescence. adolescence. Cooke and Abernathy, ${ }^{33}$ in a comparison of MRI and school performance found that the 12-13 year old subjects had a mean WISC IQ of 88 , although there appeared to be no correlation between MRI abnormality and IQ, motor impairment, or frequency of attention deficits. Rushe et al found (in a subgroup of our study cohort) that verbal fluency scores at 15 years were significantly reduced compared with term controls, although a range of other neuropsychological tests gave results similar to controls. ${ }^{34}$

A population based study from the Netherlands ${ }^{34 a}$ recently reported that at 14 years, $27 \%$ of a cohort of preterm babies required special educational assistance. The investigators noted that in non-handicapped preterm survivors special educational assistance was four times higher than in the general population.

Powls and colleagues ${ }^{35}$ assessed the motor skills of a cohort of very low birth weight children without major neurodevelopmental impairment at 6 years, 8 years, and 12-13 years. They found that although there was a significant improvement from 6 to 8 years of age, there was no further change at 12-13 years. At this age, however, $51 \%$ of the cohort had some degree of neuromotor impairment (scoring below the 15 th centile), with $34 \%$ being significantly impaired $(<5$ th centile).

In a cohort of very low birth weight children, Botting and colleagues $^{36}$ noted deterioration in cognitive measures performed at 12 years compared to 6 years. In particular they noted an increase in the proportion of children with mild cognitive impairment. However, they also found an apparent deterioration in a group of classroom matched term controls, over the same time period. They concluded that the comparable drop in IQ in both groups could be accounted for by the revised standardisation of the WISC test in 1992.

A longitudinal study comparing assessment at 4, 9, and 19 years of age failed to show a decline in a preterm cohort of infants and instead showed that there was a slight decline in the performance of full term controls. ${ }^{37}$ However, the population studied consisted of infants born between 27 and 32 weeks of gestation and different assessment tools were used at the different ages. Saigal and colleagues ${ }^{38}$ found a decline in mathematical skills between the ages of 8 and

Table 4 Neuromotor test results

\begin{tabular}{|c|c|c|}
\hline $\begin{array}{l}\text { Neuromotor categories } \\
(n=149)\end{array}$ & $\begin{array}{l}8 \text { years }(n=150) \text {, } \\
n(\%)\end{array}$ & $\begin{array}{l}14-15 \text { years } \\
\text { ( } n=149), n(\%)\end{array}$ \\
\hline Normal & $122(82)$ & $98(65)$ \\
\hline Impaired & 20 (13) & $45(30)$ \\
\hline Disabled & $8(5)$ & $6(4)$ \\
\hline
\end{tabular}


Table 5 Educational attainment and provision of assistance

\begin{tabular}{lcc}
\hline & $\mathbf{8}$ years & $\mathbf{1 4 - 1 5}$ years \\
\hline Achievement satisfactory & $112(74)$ & $96(64)$ \\
Teacher not satisfied & $14(9)$ & $10(7)$ \\
Referred to educational psychologist & $1(1)$ & $4(3)$ \\
Extra help in class (mainstream school) & $12(8)$ & $22(15)$ \\
Repeating a year & $1(1)$ & $4(3)$ \\
Behavioural problem only & $1(1)$ & $0(0)$ \\
Special school & $10(7)$ & $11(7)$ \\
\hline Wilcoxon rank test, $\mathrm{p}=0.004$ for whole model.
\end{tabular}

teen years in a cohort of extremely low birth weight subjects despite the very high uptake of extra educational support which was required by approximately half of the subjects. This finding was independent of IQ, which remained stable over the same time.

In our study the same version of the WISC test was employed at both 8 and 15 years and the same subtests were performed at both ages. No correction for prematurity was performed at either age. It seems unlikely that the consistent decline in test performance with cognitive, neuromotor, and educational measures can be explained by an artefact of test standardisation.

Other hypotheses which might explain our findings are as follows. Firstly, there is a marked increase in the demands of cognitive processing and educational performance required at 15 years compared with 8 years. As preterm survivors are known to have a high incidence of minor cerebral white matter injury, 32 the normal developmental maturation of processing abilities may be altered or delayed. GoldmanRakic ${ }^{39}$ concluded that cognitive function at a young age is located in subcortical areas, and only with increasing age does the cortex become functionally important. This model could offer an underlying neuropathological explanation for our findings. If, as we suspect, there is disruption to the higher centres of the brain during the perinatal period and that those areas only become functionally important at a later age, it would follow that deficits would only manifest themselves at a later stage. In a study of disabled children, Burack and colleagues ${ }^{40}$ found a consistent deterioration in cognitive function in older children with Down's syndrome, although there was no decline in the functioning of a group of children with cerebral palsy of multiple aetiologies.

Secondly, the association between preterm birth and adverse socioeconomic circumstances ${ }^{29-31} 36{ }^{41-43}$ could imply that some children with minor special educational needs may be deprived of appropriate educational and therapeutic support to enable them to fulfil their potential. This is consistent with our finding that only $15 \%$ of our cohort were receiving extra educational assistance at 8 years of age, compared with significantly higher rates of extra educational provision in comparable studies in New Zealand and the Netherlands. ${ }^{29}{ }^{30}$ It is likely that some ex-premature children are particularly vulnerable to the effects of an unfavourable family and educational environment. Furthermore, detailed study of the interaction between underlying cerebral pathology and these environmental factors will be of great importance in elucidating the mechanisms of adverse outcome of preterm survivors into adolescence and beyond, and the early identification of individuals at particular risk.

\section{ACKNOWLEDGEMENTS}

We would like to thank the staff of the Neonatal Unit, Children's Outpatient Department, Department of Audiology, and to Professor Brian Neville and the staff at the Wolfson Centre for allowing us to conduct interviews in their department. We are grateful to Ms Jenny Baudin and Ms Ann Seymour for conducting the psychometric tests and to Ms Janice Townsend for coordinating the follow up programme. Thanks are also due to the large number of investigators who have been involved in this project and to Mrs Alison Skinner for her technical assistance. Finally we would like to thank the subjects and their parents for their support and cooperation.

\section{Authors' affiliations}

F O'Brien, S Roth, A Stewart, J Wyatt, Perinatal Brain Research Group, Department of Paediatrics, University College, London, UK

L Rifkin, T Rushe, Institute of Psychiatry, King's College, London, UK

\section{APPENDIX}

- Impairment with disability was assigned on the basis of disabling neurological signs, seizures, hearing loss requiring the use of hearing aids, cognitive function tests (WISC-R and $\mathrm{K}-\mathrm{ABC}$ ), and tests of motor impairment (Henderson-Stott) 2 SDs below the mean and test results $<5$ th centile for visuo-motor integration (Beery) or a Rutter score $>12$.

- Impairment without disability was assigned if there were abnormal neurological signs with normal function, a high tone hearing loss (not requiring hearing aids), a cognitive function or motor impairment test result between 1 and 2 SDs below the mean, or a visuo-motor integration score between the 5 th and 10 th centiles.

- All the remaining children were assigned to a normal category.

- At 14-15 years of age classification was as above with the following differences: a Schonell reading age less than 2 SD below the mean was taken as evidence of impairment severe enough to cause disability. Those with a reading age between 1 and 2 SD below the mean were classified as impaired but not disabled. The HendersonStott test is not validated at this age group and was therefore not performed.

\section{REFERENCES}

1 Franco S, Andrews BF. Reduction of cerebral palsy by neonatal intensive care. Pediatr Clin North Am 1977;24:639-49.

2 Kudriavcev T, Schoenberg BS, Kurland LT, et al. Cerebral palsy-trends in incidence and changes in concurrent neonatal mortality: Rochester, MN, 1950-1976. Neurology 1983;33:1433-8.

3 Meberg A, Broch H. A changing pattern of cerebral palsy. Declining trend for incidence of cerebral palsy in the 20-year period 1970-89. J Perinat Med 1995;23:395-402.

4 Dale A, Stanley FJ. An epidemiological study of cerebral palsy in Western Australia, 1956-1975. II: Spastic cerebral palsy and perinatal factors. Dev Med Child Neurol 1980;22:13-25.

5 Pharoah PO, Platt MJ, Cooke T. The changing epidemiology of cerebral palsy. Arch Dis Child Fetal Neonatal Ed 1996;75:F169-73.

6 Robertson CM, Hrynchyshyn GJ, Etches PC, et al. Population-based study of the incidence, complexity, and severity of neurologic disability among survivors weighing 500 through 1250 grams at birth: a comparison of two birth cohorts. Pediatrics 1992;90:750-5.

7 Tudehope D, Burns YR, Gray PH, et al. Changing patterns of survival and outcome at 4 years of children who weighted 500-999 $\mathrm{g}$ at birth. J Paediatr Child Health 1995;31:451-6.

8 Colver AF, Gibson M, Hey EN, et al. Increasing rates of cerebral palsy across the severity spectrum in north-east England 1964-1993. The North of England Collaborative Cerebral Palsy Survey. Arch Dis Child Fetal Neonatal Ed 2000;83:F7-12.

9 Pharoah PO, Stevenson CJ, Cooke RW, et al. Prevalence of behaviour disorders in low birthweight infants. Arch Dis Child 1994;70:271-4.

10 Hack M, Taylor HG, Klein N, et al. School-age outcomes in children with birth weights under $750 \mathrm{~g}$. N Engl J Med 1994;331:753-9.

11 McCormick MC, Gortmaker SL, Sobol AM. Very low birth weight children: behavior problems and school difficulty in a national sample. J Pediatr 1990; 117:687-93.

12 Saigal S, Rosenbaum P, Szatmari $P$, et al. Learning disabilities and school problems in a regional cohort of extremely low birth weight (less than $1000 \mathrm{G}$ ) children: a comparison with term controls. J Dev Behav Pediatr $1991 ; 12: 294-300$

13 Stewart A, Hope PL, Hamilton P, et al. Prediction in very preterm infants of satisfactory neurodevelopmental progress at 12 months. Dev Med Child Neurol 1988;30:53-63. 
14 Costello AM, Hamilton PA, Baudin J, et al. Prediction of neurodevelopmental impairment at four years from brain ultrasound appearance of very preterm infants. Dev Med Child Neurol 1988;30:711-22.

15 Roth SC, Baudin J, McCormick DC, et al. Relation between ultrasound appearance of the brain of very preterm infants and neurodevelopmental impairment at eight years. Dev Med Child Neurol 1993;35:755-68.

16 Amiel-Tison C, Stewart A. Follow up studies during the first five years of life: a pervasive assessment of neurological function. Arch Dis Child 1989:64:496-502.

17 Sheridan MD. Stycar Vision Test. Windsor: NFER, 1968.

18 Henderson EH, Stott HD, Moyes FA. Test of motor impairment. London: Harcourt Brace Jovanovich, 1987.

19 Beery KE. Developmental test of visual-motor integration. Cleveland: Modern Curriculum Press, 1989

20 Wechsler D. Wechsler Intelligence Scales for Children. New York: Psychological Corporation, 1974.

21 Kaufman AS. Kaufman Assessment Battery for Children. Circle Pines: American Guidance, 1983.

22 Rutter M. A children's behaviour questionnaire for completion by teachers. J Child Psychol Psychiatry 1967;118:1-11.

23 Cannon-Spoor HE, Potkin SG, Wyatt KJ. Measurement of premorbid adjustment in chronic schizophrenia. Schizophrenia Bulletin 1982;8:470-84.

24 Rutter M, Tizard J, Whitmore K. Education, health and behaviour. London: Longman, 1970 (reprinted Melbourne: Kreiger, 1981).

25 Schonnel FJ, Schonnel FE. Diagnostic and attainment testing. 4th edn. London: Oliver and Boyd, 1960.

26 Saigal S, Szatmari P, Rosenbaum P, et al. Cognitive abilities and school performance of extremely low birth weight children and matched term control children at age 8 years: a regional study. J Pediatr 1991;118:751-60.

27 Pharoah PO, Stevenson CJ, Cooke RW, et al. Clinical and subclinical deficits at 8 years in a geographically defined cohort of low birthweight infants. Arch Dis Child 1994:70:264-70.

28 Court SDM. Fit for the future. Report of the Committee on Child Health Services. Great Britain: Department of Health and Social Security. Command 6684. Vol. 1. London: HMSO, 1976:219.

29 Horwood LJ, Mogridge N, Darlow BA. Cognitive, educational, and behavioural outcomes at 7 to 8 years in a national very low birthweight cohort. Arch Dis Child Fetal Neonatal Ed 1998;79:F12-20.

30 Hille ET, den Ouden AL, Baver L, et al. School performance at nine years of age in very premature and very low birth weight infants: perinatal risk factors and predictors at five years of age. Collaborative Project on Preterm and Small for Gestational Age (POPS) Infants in The Netherlands. J Pediatr 1994; 125:426-34.

31 Marlow N, Roberts L, Cooke R. Outcome at 8 years for children with birthweights of $1250 \mathrm{~g}$ or less. Arch Dis Child 1993;68:286-90.

32 Stewart AL, Rifkin L, Amess PN, et al. Brain structure and neurocognitive and behavioural function in adolescents who were born very preterm. Lancet 1999;353:1653-7.

33 Cooke RW, Abernethy $\sqcup$. Cranial magnetic resonance imaging and school performance in very low birth weight infants in adolescence. Arch Dis Child Fetal Neonatal Ed 1999;81:F116-21.

34 Rushe TM, Rifkin L, Stewart AL, et al. Neuropsychological outcome at adolescence of very preterm birth and its relation to brain structure. Dev Med Child Neurol $2001 ; 43: 226-33$,

34a Den Ouden L, Hille E, Verrips E, et al. Preterm birth, sentence to life? [abstract]. Pediatr Res 2001;49:272.

35 Powls A, Botting N, Cooke RW, et al. Motor impairment in children 12 to 13 years old with a birthweight of less than $1250 \mathrm{~g}$. Arch Dis Child Fetal Neonatal Ed 1995;73:F62-6.

36 Botting N, Powls A, Cooke RW, et al. Cognitive and educational outcome of very-low-birthweight children in early adolescence. Dev Med Child Neurol 1998;40:652-60.

37 Tideman E, Ley D, Bierre I, et al. Longitudinal follow-up of children born preterm: somatic and mental health, self-esteem and quality of life at age 19. Early Hum Dev 2001;61:97-110.

38 Saigal S, Hoult LA, Streiner DL, et al. School difficulties at adolescence in a regional cohort of children who were extremely low birth weight. Pediatrics 2000;105:325-31.

39 Goldman-Rakic PS. Topography of cognition: parallel distributed networks in primate association cortex. Ann Rev Neurosci 1998;1 1:137-56.

40 Burack JA, Hodapp RM, Zigler E. Toward a more precise understanding of mental retardation. J Child Psychol Psychiatry 1990;31:471-5.

41 Hagan R, Pope S, French N, et al. Postnatal depression; impact on child behavioural and the family [abstract]. Pediatr Res 1999;45:923.

42 Pescoe J, Lanzi R, Phillips M, et al. Mothers' depressive symptoms and their children's acquisition of reading and maths skills: a national longitudinal study [abstract]. Pediatr Res 1999;45:921.

43 Resnick MB, Gueorguieva RV, Carter RL, et al. The impact of low birth weight, perinatal conditions, and sociodemographic factors on educational outcome in kindergarten. Pediatrics 1999; 104:e74.

\section{Congenital heart disease and maternal diabetes}

ome $0.6-0.8 \%$ of liveborn babies have congenital cardiovascular malformations. For

babies whose mothers have diabetes retrospective studies have put the rate at around

2-4\%. A prospective population based study in the north of England has provided more data (Christopher Wren et al. Heart 2003;89:1217-20).

The population studied has a recent live birth rate of around 32000 a year. In the study years, 1995-2000, there were 192618 live births, 609 to mothers with pre-existing diabetes. Cardiovascular malformations were diagnosed before the age of 12 months in 1417 babies of non-diabetic mothers $(0.74 \%)$ and in 22 babies of diabetic mothers $(3.6 \%)$. The malformations found among infants of diabetic mothers in this study were taken together with those reported in five previous studies and compared with the findings among infants of non-diabetic mothers. Transposition of the great arteries, tricuspid atresia, and truncus arteriosus together constituted $5.6 \%(4.3 \%, 0.4 \%$, and $0.9 \%$ respectively) of cardiovascular malformations in infants of non-diabetic mothers and $21.6 \%(14.4 \%, 3.2 \%$ and $4.0 \%)$ in infants of diabetic mothers. It is estimated that these three malformations are at least 15 times more prevalent in liveborn infants of mothers with diabetes. Data from the Northern Congenital Abnormality survey show that at least $2.8 \%$ of babies born with transposition between 1985 and 2000 had mothers with diabetes. This contrasts with the $0.32 \%$ prevalence of diabetes among all mothers in the prospective 1995-2000 study. Among the 609 women with diabetes in this study a cardiovascular malformation was diagnosed antenatally in 12 and postnatally in 12. Two affected fetuses, both with left atrial isomerism, died in utero. During the study period 92 non-diabetic pregnancies with a fetus with cardiovascular malformation were terminated.

Mothers with pre-existing diabetes have a fivefold increase in the risk of having a baby born alive with a cardiovascular malformation. Transposition of the great arteries, truncus arteriosus, and tricuspid atresia are the malformations particularly associated with maternal diabetes. 